\title{
Elevation of Pseudoskusea, Rusticoidus and Protomacleaya to valid subgenera in the mosquito genus Aedes based on taxon naming criteria recently applied to other members of the Tribe Aedini (Diptera: Culicidae)
}

\author{
Richard C. Wilkerson ${ }^{{ }^{*}}$ and Yvonne-Marie Linton ${ }^{1,2,3,4}$
}

\begin{abstract}
Background: Pseudoskusea, Rusticoidus and Protomacleaya were well-recognized, morphologically distinct subgenera within the genus Aedes prior to a series of taxonomic changes over the past 15 years by Reinert, Harbach and Kitching, when they were recognized as subgenera of the genus Ochlerotatus. In our recent effort to stabilize the Tribe Aedini, we synonymized these subgenera and associated species back into the genus Aedes, but incorrectly assigned them as putative informal groups, instead of reinstating them to subgenera.

Conclusion: Here we formally elevate three traditionally recognized subgenera (Pseudoskusea, Rusticoidus and Protomacleaya) within the genus Aedes.
\end{abstract}

Keywords: Tribe Aedini, Aedes, Subgenera, Elevation

\section{Findings}

The tribe Aedini is comprised of about a third of all recognized mosquito species, and includes many vectors of debilitating viral diseases to humans, such as Dengue and Chikungunya. Within the tribe, the genus Aedes, in the traditional sense, is the largest genus in the tribe with 932 species. Other aedine genera are Armigeres, Eretmapodites, Haemagogus, Heizmannia, Opifex, Psorophora, Udaya and Verrallina. During the past 11 years, based on a series of morphological phylogenetic studies by Reinert, Harbach \& Kitching (RH\&K) [1-4], and the taxonomic actions resulting from those studies, the original genus Aedes was split into 74 genera, reducing the genus Aedes from over 900 species [5-8], to only 12 . Chief among the reasons given by

\footnotetext{
* Correspondence: wilkersonr@si.edu

'Department of Entomology, National Museum of Natural History,

Smithsonian Institution, Washington, DC, USA

Full list of author information is available at the end of the article
}

RH\&K to elevate so many genera was the author's claim of an unreferenced "principle of equivalent rank." This implied that if traditionally accepted genera were phylogenetically co-equal with other clusters of species in their analyses, the newly recognized groups should also be given similar taxonomic status. These taxonomic actions were highly controversial $[9,10]$ and resulted in wide-spread confusion about which names to apply to most vectors of disease organisms in genus Aedes (see Table one in [12]). For example, during this period, Aedes japonicus (Theobald), an invasive species and proven vector of West Nile virus and Cache Valley virus, was known variously as Aedes (Finlaya) japonicus [5], Ochlerotatus (Finlaya) japonicus [11], 'Ochlerotatus' ('Finlaya') japonicus [1] and Hulecoeteomyia japonica [2].

Close scrutiny of the RH\&K phylogenetic results and a reanalysis of their dataset led Wilkerson et al. [12] to the conclusion that based on the evidence provided by RH\&K the classification changes they promoted and that 
resulted in the split of the well-known genus Aedes into so many genera, were not warranted. Aedes was therefore reinstated [12], but to preserve their phylogenetic hypotheses the RH\&K genera were reduced in rank to subgenera of Aedes. Any subgenera in the fragmented $\mathrm{RH} \& \mathrm{~K}$ system were reduced to putative informal group status [12]. Rationalization for reinstatement of genus Aedes to include all "traditionally" accepted species was based on opinions promoting a conservative approach to classification change based on new phylogenetic analyses [13-15]. These opinions were comprehensively solidified by Vences et al. [16] who, in detail, discussed the relationship between nomenclatorial utility and phylogenetic accuracy. As a guide to determine the suitability for classification changes they proposed a number of Taxon Naming Criteria (TNCs). Appropriate TNCs were cited to reinstate the "traditional" species in genus Aedes [12]. Central to these arguments reinstating genus Aedes, while retaining other traditional aedine genera were: TNC 2, Clade Stability; TNC 3, Phenotypic Diagnosibility; TNC 8, Manageability; TNC 10, Nomenclatural Stability, and; TNC 11, Community Consensus. Since, to these authors [12], there was no compelling evidence warranting changing the classification of traditional diagnosable genera, the traditional genera in tribe Aedini should be retained until strong, multiple lines of evidence are produced showing the contrary.

Following our recent publication reinstating the genus Aedes [12], we revisited the above rationale and realized that three traditionally recognized Aedes subgenera (Pseudoskusea, Rusticoidus and Protomacleaya), recognized as subgenera by $\mathrm{RH} \& \mathrm{~K}$ in their genus Ochlerotatus, were incorrectly synonymized as putative informal groups [12], when they should have been reinstated as bona fide subgenera of the genus Aedes. All are diagnosable, well-known traditional groupings and should be retained as such. Taxonomic information for each subgenus, including important references and component species are given in Appendix.

\section{Conclusion and formal taxonomic action}

Here, we formally retrieve Pseudoskusea, Rusticoidus and Protomacleaya from synonymy within the Aedes subgenus Ochlerotatus [12], and elevate all three as subgenera of the genus Aedes.

\section{Appendix}

Taxonomic Catalog Citation

Subgenus Pseudoskusea Theobald 1907 (as genus) [17].

Type species: Skusea multiplex Theobald.

Subgenus Synonym Caenocephalus Taylor 1914 [18]

(not Caenocephalus van der Wulp, 1898 [19])

bancroftianus Edwards, 1921 culiciformis (Theobald, 1905)

multiplex (Theobald, 1903)

postspiraculosus Dobrotworsky, 1961

\section{Important References:}

Dobrotworsky 1961 (tax., bion.; Australia) [20]

Dobrotworsky 1965 (tax., key, bion.; Australia) [21]

Lee et al. 1984 (tax., key, distr., bion.; Australia) [22]

Reinert 2000 (to subg. of genus Ochlerotatus) [11]

Reinert 2002 (F gen.*) [23]

Reinert et al. 2006 (phyl., class.; to genus) [2]

Reinert et al. 2008 (to subg. of genus Ochlerotatus) [3]

Wilkerson et al. 2015 (phyl., class.; to syn. of subg.

Ochlerotatus of genus Aedes) [12]

Herein: to subg. of genus Aedes

Subgenus Protomacleaya Theobald 1907 (as genus) [17].

Type species: Culex trisereatus Say

aitkeni Schick, 1970

alboapicus Schick, 1970

amabilis Schick, 1970

argyrothorax Bonne-Wepster and Bonne, 1920

berlini Schick, 1970

bertrami Schick, 1970

braziliensis Gordon and Evans, 1922

brelandi Zavortink, 1972

buenaventura Schick, 1970

burgeri Zavortink, 1972

campana Schick, 1970

casali Schick, 1970

chionotum Zavortink, 1972

daryi Schick, 1970

diazi Schick, 1970

gabriel Schick, 1970

galindoi Schick, 1970

hendersoni Cockerell, 1918

heteropus Dyar, 1921

homoeopus Dyar, 1922

idanus Schick, 1970

impostor Schick, 1970

insolitus (Coquillett, 1906)

knabi (Coquillett, 1905)

kompi Vargas and Downs, 1950

metoecopus Dyar, 1925

niveoscutum Zavortink, 1972

podographicus Dyar and Knab, 1906

sandrae Zavortink, 1972

schicki Zavortink, 1972

schroederi Schick, 1970

sumidero Schick, 1970

tehuantepec Schick, 1970

terrens (Walker, 1856)

thorntoni Dyar and Knab, 1907

triseriatus (Say, 1823) 
vargasi Schick, 1970

zavortinki Schick, 1970

zoosophus Dyar and Knab, 1917

\section{Important References:}

Sourcouf \& Gonzalez Rincones 1912 (as Promacleaya: emend.) [24]

Schick 1970 (keys, Terrens Group) [25]

Schick 1970 (keys, Terrens Group) [26]

Zavortink 1972 (tax.: resurrected from syn. with Finlaya) [27]

Reinert 2000 (to subg. of genus Ochlerotatus) [11]

Reinert et al. 2009 (as 'Ochlerotatus' ('Protomacleaya) sensu auctorum) [4]

Wilkerson et al. 2015 (to syn. of subg. Ochlerotatus of genus Aedes) [12]

Herein: to subg. of genus Aedes

\section{Subgenus Rusticoidus Shevchenko and Prudkina 1973 (as subg. of genus Aedes; M*, key) [28].}

Type species: Aedes refiki Medschid

albescens Edwards, 1921

bicristatus Thurman and Winkler, 1950

krymmontanus Alekseev, 1989

lepidonotus Edwards, 1920

provocans (Walker, 1848)

quasirusticus Torres Canamares, 1951

refiki Medschid, 1928

rusticus (Rossi, 1790)

ssp. subtrichurus Martini, 1927

subdiversus Martini, 1926

\section{Important References:}

Reinert 1999 (tax., review) [29]

Reinert 2000 (to subg. of genus Ochlerotatus) [11]

Reinert 2002 (F gen.*) [23]

Reinert et al. 2008 (phyl., class.) [3]

Reinert et al. 2009 (phyl., class.) [4]

Wilkerson et al. 2015 (to syn. of subg. Ochlerotatus of genus Aedes) [12]

Herein: to subg. of genus Aedes

Important taxonomic information and key references for the three Aedes subgenera treated herein (www.mosquitocatalog.org, 13 Sept. 2015); associated species are listed by subgenera. $[$ Tax. = taxonomy, phyl. = phylogenetics, class. $=$ classification, bion. $=$ bionomics, distr. $=$ distribution, subg. = subgenus, syn. = snynomy, $*=$ all or part of life stage is illustrated, $\mathrm{F}=$ female, $\mathrm{M}=$ male, gen. = genitalia, emend. = emendation]

\section{Competing interests}

The authors declare that they have no competing interests.
Authors' contributions

RCW and YML contributed equally to the final paper. Both authors read and approved the final version of the manuscript.

\section{Acknowledgements}

We thank Bruce Harrison for careful review of the manuscript and his many helpful comments. This research was performed under a Memorandum of Understanding between the Walter Reed Army Institute of Research and the Smithsonian Institution, with institutional support provided by both organizations. This manuscript was prepared whilst YML held a National Research Council (NRC) Research Associateship Award at the Walter Reed Army Institute of Research. The material to be published reflects the views of the authors and should not be construed to represent those of the U.S. Department of the Army or the U.S. Department of Defense.

\section{Author details}

${ }^{1}$ Department of Entomology, National Museum of Natural History, Smithsonian Institution, Washington, DC, USA. ${ }^{2}$ Walter Reed Biosystematics Unit, Museum Support Center, Smithsonian Institution, Suitland, Maryland, USA. ${ }^{3}$ Department of Entomology, Walter Reed Army Institute of Research, Silver Spring, Maryland, USA. ${ }^{4}$ Faculty of Preventative Medicine and Biometrics, Uniformed Services University of the Health Sciences, Bethesda, Maryland, USA.

Received: 8 October 2015 Accepted: 8 December 2015

Published online: 30 December 2015

\section{References}

1. Reinert JF, Harbach RE, Kitching IJ. Phylogeny and classification of Aedini (Diptera: Culicidae), based on morphological characters of all life stages. Zool J Linn Soc. 2004;142:289-368. doi:10.1111/j.1096-3642.2004.00144.x.

2. Reinert JF, Harbach RE, Kitching IJ. Phylogeny and classification of Finlaya and allied taxa (Diptera: Culicidae: Aedini) based on morphological data from all life stages. Zool J Linn Soc. 2006;148:1-101. doi:10.1111/j.1096-3642. 2006.00254.x

3. Reinert JF, Harbach RE, Kitching IJ. Phylogeny and classification of Ochlerotatus and allied taxa (Diptera: Culicidae: Aedini) based on morphological data from all life stages. Zool J Linn Soc. 2008;153:29-114. doi:10.1111/j.1096-3642.2008.00382.x

4. Reinert JF, Harbach RE, Kitching IJ. Phylogeny and classification of tribe Aedini (Diptera: Culicidae). Zool J Linn Soc. 2009;157:700-94. doi:10.1111/j. 1096-3642.2009.00570.x.

5. Knight KL, Stone A. A catalog of the mosquitoes of the world (Diptera: Culicidae). 2nd ed. College Park, Maryland: Entomological Society of America; 1977. 611 p.

6. Knight KL. Supplement to a catalog of the mosquitoes of the world (Diptera: Culicidae). College Park, Maryland: Entomological Society of America; 1978. 107 p.

7. Ward RA. Second supplement to "A catalog of the mosquitoes of the world" (Diptera: Culicidae). Mosq Syst. 1984;16:227-70.

8. Ward RA. Third supplement to "A catalog of the mosquitoes of the world" (Diptera: Culicidae). Mosq Syst. 1992;24:177-230.

9. Savage HM, Strickman D. The genus and subgenus categories within Culicidae and placement of Ochlerotatus as a subgenus of Aedes. J Am Mosq Control Assoc. 2004;20:208-14.

10. Savage HM. Classification of mosquitoes in tribe Aedini (Diptera: Culicidae): Paraphylyphobia, and classification versus cladistic analysis. J Med Entomol. 2005:42:923-7. doi:10.1093/jmedent/42.6.923. PMID: 16465729.

11. Reinert JF. New classification for the composite genus Aedes (Diptera: Culicidae: Aedini), elevation of subgenus Ochlerotatus to generic rank, reclassification of the other subgenera, and notes on certain subgenera and species. J Am Mosq Control Assoc. 2000;16:175-88.

12. Wilkerson R, Linton Y-M, Fonseca D, Schultz T, Price D, Strickman D. Making mosquito taxonomy useful: A stable classification of tribe Aedini that balances utility with current knowledge of evolutionary relationships. PLoS One. 2015;10, e0133602. doi:10.1371/journal.pone.0133602.

13. Wiley EO. An annotated Linnaean hierarchy, with comments on natural taxa and competing systems. Syst Zool. 1979;28:308-37. doi:10.1093/sysbio/28.3.308.

14. Wiley EO. Phylogenetics. The Theory of Phylogenetic Systematics. New York: Wiley-Interscience; 1981. 439 p. 
15. Wiley EO, Liebermann BS. Phylogenetic Systematics. Theory and Practice of Phylogenetic Systematics. Hoboken, New Jersey: Wiley-Blackwell; 2011.

16. Vences M, Guayasamin JM, Miralles A, de la Riva I. To name or not to name: Criteria to promote economy of change in Linnaean classification schemes. Zootaxa. 2013;3636:201-44. doi:10.11646/zootaxa.3636.2.1.

17. Theobald FV. A monograph of the Culicidae or mosquitoes. London: British Museum (Natural History); 1907. 639 p.

18. Taylor FH. The Culicidae of Australia. -I. Trans Entomol Soc London. 1914;61:683-708.

19. van der Wulp FM. Dipteren aus Neu-Guinea in der Ungarischen NationalMuseums. Termeszetrajzi Fuzetek, kiadja a Magyar nemzeti Muzeum, Budapest. 1898;21:409-26.

20. Dobrotworsky NV. Notes on Australian mosquitoes (Diptera, Culicidae). V. Subgenus Pseudoskusea in Victoria. Proc Linn Soc New South Wales; 1961. 257-267.

21. Dobrotworsky NV. The mosquitoes of Victoria (Diptera, Culicidae). London and New York: Melbourne University Press; 1965. 237 p.

22. Lee DJ, Dyce AL, O'Gower AK. The Culicidae of the Australasian region, vol 3. Canberra, Australia: Australian Government Publishing Service; 1984.

23. Reinert JF. Comparative anatomy of the female genitalia of genera and subgenera in tribe Aedini (Diptera: Culicidae). Part XIII. Ochlerotatus Lynch Arribalzaga. Cont Amer Entomol Inst. 2002:33:1-117.

24. Surcouf J, Gonzalez-Rincones R. Dipteres piqueurs et suceurs de sang actuellement connus de la Republique de Venezuela. Archives de Parasitologie Paris. 1912;15:248-314.

25. Schick RX. Mosquito studies (Diptera, Culicidae) XX. The terrens group of Aedes (Finlaya). Cont Amer Entomol Inst. 1970;5:1-158.

26. Schick RX. Mosquito studies (Diptera, Culicidae) XXIII. Additions and corrections to the revision of the Aedes terrens group. Cont Amer Entomol Inst. 1970;7:13-40.

27. Zavortink TJ. Mosquito Studies (Diptera, Culicidae) XXVIII. The new world species formerly placed in Aedes (Finlaya). Cont Amer Entomol Inst. 1972:8:1-206.

28. Shevchenko AK, Prudkina NS. On morphology of genitals in mosquito males from the Aedes genus. Vestnik Zoologii. 1973;6:40-7.

29. Reinert JF. The subgenus Rusticoidus of genus Aedes (Diptera: Culicidae) in Europe and Asia. Europ Mosq Bull. 1999;4:1-7.

\section{Submit your next manuscript to BioMed Central and we will help you at every step:}

- We accept pre-submission inquiries

- Our selector tool helps you to find the most relevant journal

- We provide round the clock customer support

- Convenient online submission

- Thorough peer review

- Inclusion in PubMed and all major indexing services

- Maximum visibility for your research

Submit your manuscript at www.biomedcentral.com/submit 